\title{
Study on the Innovation and Entrepreneurship Education of Chinese Universities under Economic New Normal
}

\author{
Minghui Long ${ }^{1, a}$ and Yuehua Bai ${ }^{2, b^{*}}$ \\ Wuhan Donghu University, Wuhan, Hubei, China \\ 642604051@qq.com \\ *The Corresponding author
}

\begin{abstract}
Keywords: Economic new normal; Entrepreneurship; Innovation; Entrepreneurship education
\end{abstract}
\begin{abstract}
Chinese economy presents a new normal. This means a shifting of economic growth rate from high-speed growth to medium-to-high speed of growth, unceasingly optimization and upgrade of economic structure, more diversified growth momentum and a significant impact on the global economic development. The economic new normal present both challenges and opportunities for entrepreneurship, only those who take the initiative to deepen the reform and promote innovation can grasp the initiative of economic growth. Innovation and entrepreneurship education is the education that aims at cultivating the talent with basic quality of entrepreneurship and pioneering personality and focus on fostering the sense of entrepreneurship, innovation spirit and innovation and enterprise capability of the students. Its essence is a practical education. College students have grown into an important player of entrepreneurship, and as a group of young high level intellectual, they are more willing to engage in high-tech and high value-added work. Therefore, to explore the college entrepreneurship education and enhance the success rate of graduate entrepreneurship is of great significance to serving the society and economic development.
\end{abstract}

\section{Introduction}

With the gradual improvement of quality and benefit of China's economic development and the transformation from factor input drive to innovation drive, technological development and comprehensive innovation has become the fundamental driving force for China's economic development. Under the new normal, the government has been promoting the deepening of reform, the adjustment of the development mode and the system, so the entrepreneurial environment will bring new changes. The central economic work conference held in December 2014 requires grasping and understanding the stage characteristics of "new normal" in China's economic development from the historical and dialectical point of view. The reason why China transformed into the "new normal" economic development is that economic mode of the traditional quantitative expansion featured high-investment, high-energy and high-pollution need to be adjusted, especially in the context of the increase of factor cost and decrease of resource allocation efficiency and factor supply. This shows that economic development in the "new normal" can only achieve the transformation by depending on the progress of the quality of human capital and science and technology and transformation from factor drive, investment drive to innovation drive.

Premier Li Keqiang put forward the keyword of "widespread entrepreneurship and innovation" in the Summer Davos Forum held in September 2014. He then brought forward the promotion of widespread entrepreneurship and innovation in the report on the work of the government in 2015. Ministry of Education pointed out in the Opinion of Vigorously Promoting the Innovation and Entrepreneurship Education in Colleges and Universities and the Work of Self-employment of College Students that "to conduct innovative entrepreneurship education in the colleges and universities and encourage self-employment of college students are the major strategic initiatives for the education system to carryout in-depth learning and practice the scientific concept of development and serve the construction of innovative countries; the important way of deepening the reform of higher education, cultivating the innovative spirit and practical ability of the student; the important measure of promoting the employment through business startup and promoting the full 
employment of college graduates". How to cultivate students' innovative and entrepreneurial ability attracts the wide attention from the society. It is not only the need of the times to study innovation and entrepreneurship education, but also the need of the educational reform and development in China.

\section{An analysis of the Innovative Entrepreneurial Environment under the Economic New Normal}

Innovation and entrepreneurship play a very important role in economic and social development. It generates new organizations and industries, which is conducive to the improvement of the economic system and promotion of the economic growth. A region's economic development is closely related to the region's innovative entrepreneurial activities. The development and flourish of innovative entrepreneurial activities depends on a certain entrepreneurial environment, because the environment directly affects the innovation and entrepreneurial activities organized by the enterprise. The innovative entrepreneurial environment for college students includes both the hard environment and the soft environment. The hard environment mainly refers to the infrastructure construction, and the soft environment mainly includes the entrepreneurial atmosphere, entrepreneurship service assurance and the related entrepreneurship policies.

Innovative and Entrepreneurial Ecological Environment .The sound development of "widespread entrepreneurship and innovation" requires building a coordinated entrepreneurship and innovation system between government, enterprises and individuals. This system includes colleges and universities, government, enterprises, families, students and other subsystems. The interrelation, interaction and mutual support of each subsystem constitute a complete innovation and entrepreneurship education system. Colleges and universities play a key role in the innovation and entrepreneurship education system, because student is the ultimate goal of innovation and entrepreneurship education. Only when the students accept the innovation and entrepreneurship concepts, understand the quality requirements for innovative talents, master the basic knowledge needed to carry out entrepreneurial activities and the necessary entrepreneurial ability and have the courage to practice innovation and entrepreneurship, can we say that innovation and entrepreneurship education has produced practical results.

Government Policy. Favorable business environment will affect the success of entrepreneurship, and as an important element of entrepreneurial environment, entrepreneurial policy bears on the smooth development of entrepreneurial activities. In recent years, the central government has introduced preferential policies to encourage college students to start business, and the local government departments have also established entrepreneurial park and entrepreneurship education and training center for college students. But such entrepreneurial education policies, entrepreneurial financing policies and entrepreneurial environment policies need to be further studied in the entrepreneurial practice.

Ministry of Human Resources and Social Security put forward requirements for the sites and facilities of college students pioneer park in the Notice on the Implementation of the Lead Plan of College Students Entrepreneurship in 2010 and made clear the construction goals and specific tasks, such as the establishment of entrepreneurial practice base or incubation base for college students, so as to provide support for graduate entrepreneurship in such fields as space, training, fund, services, etc. The pioneer park for college students is a base to provide service for innovation and entrepreneurship of college students and promote the transformation of the achievements. The costs for pioneering enterprises of college students is reduced and the success rate is improved with a series of preferential policies being implemented in place, such as providing office space, consultation and training, management and services, etc.

Construction of Incubation Base for Innovation and Entrepreneurship of College Students .The incubation base for graduate entrepreneurship is a new type of social and economic organizations with the purpose of serving the youth to start business, providing sites for research and development, production and operation, and other facilities for office, communication, network, etc., and providing strong support in such fields as education and training, information consultation, policy assurance and financing channel, etc., so as to reduce the cost and risk for college students' 
innovative undertaking and ensure the survival rate and success rate in this regard. The incubation base for graduate entrepreneurship plays an active role in helping college students to start their own businesses, obtain employment, and relieving the pressure of social employment, cultivating innovative talents and promoting social and economic development. In 2010, Ministry of Education required the establishment of entrepreneurial practice base or incubation base for college students to provide support in such fields as site, training, financial services, etc., and reduce and cancel rent for start-up enterprises of college students for at least 12 months. In recent years, thousands of practice bases and business incubation bases for college students have been established throughout the country with various preferential policies, which play a prominent role for the development of start-up enterprises of college students.

Incubation base is service-oriented, reflecting the public welfare nature. Public welfare is the starting point of the construction of incubation base for college students. The public welfare nature of college students' incubation base is reflected in its consistent support to college students' entrepreneurship with its own advantages. The problems of the college students entrepreneurship in the stage of starting point lie mainly in such fields as technology, commerce and financing, and the incubation base is to provide these services, create suitable environment for college students entrepreneurship, so as to ensure the growth and maturity of graduate entrepreneurship.

\section{The Bottleneck of Further Development of Innovative Entrepreneurship Education for Chinese Colleges and Universities}

Entrepreneurship education research and practice began early in Europe and the United States, which has formed a complete system at present. Compared with the development of foreign entrepreneurship education, China starts relatively late in this regard. In order to encourage college students to start their own businesses, governments of all levels from the central to local have introduced a series of promotional policies. Generally, China lacks the theoretical basis and theoretical guidance in the formulation and implementation of entrepreneurship policy and the systematisms and comprehensiveness in the formulation of the policy in this regard.

Low Success Rate of College Students Entrepreneurship. In the current social and economic situation, college graduates have more market opportunities than that in the past in starting a business. The recent years have witnessed a rising proportion of entrepreneurship. According to the data in 2016 Chinese College Students Graduation Report released by the authoritative education institutions My COS, about 204,000 college students chose to start a business in 2015, the proportion of self-employed entrepreneurs is $3.0 \%, 0.1 \%$ higher than that in 2014 with the fields mainly concentrating on education industry, retail commerce, internet startup and accommodation and catering industry. Although the self-employed rate of college students has risen, it has been hovering at a relatively low level, and there is still a large gap for China compared to the $20 \%-30 \%$ of entrepreneurial rate in western developed countries.

Backwardness of Innovation and Entrepreneurship Education Concept. In May 2015, the Opinions on Deepening the Implementation of the Reform on Innovative and Entrepreneurship Education for Colleges and Universities (GBF [2015] No. 36) released by the State Council clearly pointed out that "the backwardness of innovation and entrepreneurship education concept, loose combination with professional education and the disconnection with the practice are the outstanding problems existing in the university innovation and entrepreneurship education. The core content of the innovation and entrepreneurship education is the cultivation of ambition and skill, innovation and entrepreneurship education in a broad sense is to cultivate person with ambition and self-confidence, and in the narrow sense, it is to associate with the vocational training of the college students and the enhancing of survival ability. Nowadays, innovation and entrepreneurship education puts more emphasis on the construction of knowledge system and method system, ignoring the construction of value system, which directly affects the effectiveness of innovation and entrepreneurship education. College education and teaching still stay at the level of imparting explicit knowledge and skills, and lack education on the entrepreneurial spirit and entrepreneurial value. There are biases against innovation and entrepreneurship, such as "great risk in 
entrepreneurship, entrepreneurship is a thing for people with strong ability", etc. Facing with serious social reality, college students are easy to lost in confusion without the guidance of correct innovation entrepreneurial education values.

Innovation and Entrepreneurship Education Courses are not Tightly Integrated with Specialties. What the colleges and universities are basically engaged in is employment education, which is limited in providing information, interpreting policies and regulations, as well as specific interview skills. There are little colleges and universities that have complete entrepreneurship education course system and include entrepreneurship education into the school teaching plan and carry out targeted guidance for the entrepreneurial activities of students. In addition, as the colleges and universities attach great importance to the results of innovation and entrepreneurship education for a long time, insufficient attentions are paid to the formation mechanism of carrying out result. Most of the elective innovation and entrepreneurship education courses also stay in the level of imparting operation and skill, leading to the disconnection between the innovation and entrepreneurship education and professional education and the learning of basic knowledge. There are still great limitations on the choice of teaching materials. In foreign countries, many colleges and universities have set up systematic entrepreneurship education courses and degrees to promote the effective popularization of entrepreneurship education, the universities, such as the University of Chicago, Massachusetts Institute of Technology, Stanford University, are all studying entrepreneurship education, but China is still lack of systematic teaching materials. These problems make China's innovation and entrepreneurship education lacking of an in-depth foundation.

\section{Thoughts and Measures for the Effective Implementation of Innovation and Entrepreneurship Education under the Economic New Normal}

Optimize the ecological environment for innovation and entrepreneurship and construct the sustainable development mode for innovation and entrepreneurship in colleges and universities We will provide work space, cyberspace, social and cultural space and resource share space for the entrepreneurs featured low cost, convenient and all-factor by making effective use of the college incubators and the existing resources and basic conditions of other service agencies, optimizing and improving the services formats and operating mechanism of new entrepreneur service agency and building an open entrepreneurial ecosystem of "mutual help" and "user participation". We will integrate the entrepreneurial culture into the campus culture construction areas, strengthen publicity, and actively support all kinds of innovative entrepreneurship competition by making full use of the campus culture carrier with emphasis on entrepreneurial auditorium, entrepreneurship forum, entrepreneurship training camp and other types of entrepreneurship training, so as to create a positive atmosphere to fully stimulate students' enthusiasm for entrepreneurship. Improve the entrepreneurial counseling mechanism, encourage entrepreneurs, angel investors to serve as an enterprise mentor. We will promote entrepreneurship education curriculum to enter into the classroom and organize the science and technology festival and other activities combing the school characteristics and professional advantages, so as to improve the quality of activities and expand the impact, stimulate students' enthusiasm for entrepreneurship and improve the student's entrepreneurial skill.

Expand the Object of Education and Completely Update the Knowledge System .Expand the scope of objects of education, explore specific modes of education oriented to the all students. Innovation and entrepreneurship education is not simply to teach students how to start a business, but to improve students' quality in innovation and entrepreneurship. Based on this ideology, the colleges and universities are required to get rid of the "conceptual barriers" getting in the way of carrying out innovation and entrepreneurship education in practice, expand the scope of educational object and explore the specific measures for the "construction of entrepreneurial university" in terms of the institutional mechanisms and team building.

We will deepen the reform of innovation and entrepreneurship education in colleges and universities and to promote the comprehensive reform of higher education and make the two closely connected by updating the knowledge system comprehensively and taking the characteristics of 
school into consideration, so as to determine the main way of "combination of professional education" and clarify the objectives and requirements of innovation and entrepreneurship education and the orientation of talent cultivation, so as to excavate and enrich all innovation and entrepreneurship education resources for all kinds of professional courses. Above all, we will permeate the idea and content of entrepreneurship education in the professional education and teaching, and strengthen innovation and entrepreneurship education in the process of imparting professional knowledge. We need to further promote the communication and connection between colleges, universities and governments as well as enterprises in order to promote the training and promotion for the entrepreneurial quality of all students, and explore the establishment of new mechanism of cooperative education between schools, schools and enterprises, schools and locals, schools and institutions and international cooperation. Above all, we will energetically attract the social resources and other quality educational resources to invest in innovative entrepreneurship talents, so as to move forward the in-depth reform of innovation and entrepreneurship education in colleges and universities.

Improve the Innovation and Entrepreneurship Education Curriculum System and Strengthen the Construction of Teachers. Implement the requirements of "orienting all college students and including into the main channel of teaching" regarding to innovation and entrepreneurship education curriculum made by the Ministry of Education. Make clear the subject status of entrepreneurship education and make it one of the basic content of quality-oriented education. Combine the innovation and entrepreneurship education with professional education and include innovation and entrepreneurship education into the professional courses. Promote the implementation of teaching model reform from task-driven, project-oriented to integrated teaching. Enhance the connection of professional practice and entrepreneurial practice and cultivate the entrepreneurial practice skills of student in professional practice. Leaders and teachers of professional disciplines and counselors should guide the students to recognize the correlation between professional skills and entrepreneurial skills. We will strengthen innovation in teaching materials and optimize the teaching content to carry out excellent course construction. We will strengthen teaching and research, actively promote teaching reform, strive to improve the teaching conditions, introduce interactive teaching, role play, case analysis, situational simulation training and other teaching methods. We will cultivate students into a nonconformity talent with broad vision, full of vitality, active learning, the courage to practice, management abilities.

Innovation and enterprise education has a high demand on teachers who need to both have the relevant theoretical knowledge of the subject and some entrepreneurial experience. The school need to integrate all kinds of resources, strengthen the construction of "double-qualified" teacher team, innovate the mutual authentication mechanism of double-qualified" teachers professional title and vocational qualification certificate, encourage teachers to hold "professional instructor", "career planner" "psychological counselor" and other certificates. We will carry out training for teaching staff who teach the course of college students entrepreneurship education, select core and outstanding teachers for exchange, striving to cultivate and select academic leaders with certain impact on entrepreneurial education. We will continue to push forward the teaching mode for innovation and entrepreneurship in colleges and universities, which takes the scientific research, theory and practice as the core to effectively solve the disconnection between the "curriculum design and business needs" and cultivate innovative talents for colleges and universities by making full use of research and development and industrialization process of technological projects. At the same time, through the cooperation between schools and enterprises, provide practice and internship opportunities for students to promote sustainable career development and innovation and entrepreneurship ability for students.

Improve the Quality Evaluation System of Innovation and Entrepreneurship Education of Chinese Universities. In order to carry out the innovation and entrepreneurship education for college students effectively, it is necessary for colleges and universities to establish the evaluation mechanism on the policy system of innovation and entrepreneurship, and conduct analysis on the 
value factors and defacto factors in policy implementation through certain procedures and steps based on certain value standards and defacto standards, so as to make appropriate judgments for the policy results and direction of policy, improve the policy system to enhance the quality of innovative entrepreneurship education. The daily management of training program for the graduate entrepreneurship should be included in the undergraduate teaching management system by developing practical management methods and supporting policies and carrying out evaluation on the effectiveness of existing policies on a regular basis, so that the problems can be found earlier, thus ensuring the systematicness and effectiveness of the innovation and entrepreneurship education activities.

\section{Acknowledgements}

This work was supported by the grants from Hubei Provincial Collaborative Innovation Centre of Agricultural E-Commerce (under Construction) (Wuhan Donghu university research [2015] No. 11 Document

\section{References}

[1] Jianxin Ge. Entrepreneurship[M].Beijing: Qinghua University press,2004.

[2] Yingjie Wang. Entrepreneurship Education Course[M].Beijing: China's Railway Publishing Press, 2000.

[3] Tianhu Luo Entrepreneurship course[M].Xian: Northwestern Polytechnical University press, 2004.

[4] Donald F.Kuratko, The Emergence of Entrepreneurship Education: Development, Trends, and Challenges, Entrepreneurship Theory and Practice,2005,(9):577-597.

[5] Entrepreneurship Higher Education, Especially Within Non-Business Studies,Final Report of The Expert Group European Commission,2008:15-21.

[6] Yiming He, Lei Luo. The development of entrepreneurship education in China and foreign countries and its significance to China's Higher Education[J]. Higher education exploration, 2007, (1:71-73.)

[7] Lifang Li. An analysis of entrepreneurship education in American Universities[J]. Higher education exploration, 2012,(4): 57-61.

[8] Zhiyong Li. Entrepreneurship Education in Japanese Universities[M].Hangzhou: Zhejiang Education Publishing press.

[9] Teece D J.Business strategy and innovation[J].Long range planning,2010,43(2):172-194.

[10] Marina Solesvik, Paul Westhead, Harry Marry Matlay. Cultural factors and entrepreneurial, intention: the role of entrepreneurship education[J].Education+Trainging,2014:8-9. 